\title{
Legislative tendency to incorporate renewable energy in the Spanish Electric Power Production Market
}

\author{
Mabel Gámez ${ }^{1}$ and Ricard Bosch ${ }^{2}$ \\ Department of Electrical Engineering \\ E.T.S.E.I.B. Polytechnic University of Catalonia \\ Av. Diagonal 647 - 08028 Barcelona (Spain) \\ e-mail1': mabelg@mixmail.com, e-mail²: bosch@ee.upc.edu
}

\begin{abstract}
This paper presents an overview of the current situation of the special regime generation in Spain. Whether the special regime generator decides to take part in the de-regulated Electric Power Production Market or not (regulated tariffs). It introduces the big growth of installed power of renewable producers in these last years, thanks to the economic incentives and feeding tariffs. It focuses on renewable energy generators, and also comments the problems and opportunities they have in the organised Electric Power Production Market.
\end{abstract}

Key words: special regime generator, renewable energy generators, system operator, market operator, deviation, feeding tariffs.

\section{Introduction}

Since the second Petrol crisis, special regime producers have been regulated (1980). Government objectives' were to improve the energetic efficiency and to lower the energetic dependence. Some actions were taken in this direction: promote the self-producers, renewable and cogeneration ones. Some Laws, Royal Decrees and National Energetic Plans were approved (the present is valid 2005-2010) [3].

Last international thrust was the signature of Kyoto protocol by 141 countries that are the responsible of the $61 \%$ of the total $\mathrm{CO}_{2}$ and methane emissions in the whole world. They undertook to reduce the level of contaminant evacuated to atmosphere to the levels of the 1990. The production of electricity and the refinery industries represent the $30 \%$ of the total emissions, because they use as combustible fossil sources.

Spain not only has not reduced its share in emissions, but also has tripled its emissions due to the huge economic growth. To palliate this tendency, Spanish government has approved a new Plan to develop renewable energies, buys shares of $\mathrm{CO} 2$ emissions to seller countries, buys foreign reforest and establishes saving and energetic efficiency strategies.

The objective in Spain is to have the $12 \%$ of the total consumption in 2010 covered by renewable energy.

As the Electric Power Production Market started in 1998 [1], the incomes of producers (ordinary and special regime) changed from a regulated system with fixed prices to a liberalised market with volatility of prices.
In 2007, the whole Spanish Market will be liberalised and the stranded costs will be totally settled and finished. Up to then, some special regime producers can maintain their inclusion on regulated tariffs with almost fixed prices.

\section{Current Legislation Scene}

Special regime producers follow the next Royal decree laws [2], [4] in the sense of:

\section{A. Economic regime:}

RD 2366/94 introduces classifications of each generator in groups, establish regulated price for each group, and bind together with the existence of stranded costs. RD $2818 / 97$ adds the possibility of variable retribution depending on the price pool plus feeding tariff, establish a more detailed classification of technologies, limits the energy able to be sold to the surplus one, valid till ends of 2006. RD 841/2002 allows entering in market with a seller's collection right calculated with the price pool plus feeding tariff plus power guarantee, abolished by RD 436/2004.

That last one decree, permit two possible retributions:

1) Regulated. Price related to medium reference tariff, but diminished with the penalty of deviations.

2) Liberalised. Selling in to the market and getting the price pool plus power guarantee (like any other ordinary producer) plus feeding tariff plus incentive. The feeding tariff and the incentive are related to the general system tariffs estimated by the government for the present year. In this case special producers have also to pay for their own deviations like any other market agent, through market settlement.

The RD 436/2004 obliges special producers with more than $50 \mathrm{MW}$ installed power to sell their surplus production in the pool.

The RD 436/2004 gives the possibility to the special generators included in RD 2366/94 to sell their surplus 
energy in liberalised market, during at least one year, after that period of time, they can choose between returning to the regulated tariffs or continue in market with the present $\mathrm{RD} 436 / 2004$. But if the generators included in RD 2818/97, decide to sell their surplus energy in market applying RD 436/2004, there is no way back to the RD 2818/97, they stay in these conditions.

In all these economic regimes there is also the concept of compensation the reactive power, which means an income ( $\cos \varphi$ close to 1$)$ or a penalty in their invoicing.

\section{B. Technical characteristics:}

RD 2018/97 and RD 385/2004 establish the place to install the statutory electrical meters in order to separate clearly the different activities: special generation from network distribution or transport. These statutory meters have to accomplish high level of accurateness: class and precision.

RD 1955/2000 clarifies the maintenance and lecture responsibilities of statutory meters producers possess.

RD 1433/2002 establishes the requirements of measurement for the special producers connected to low voltage distribution network.

RD 1454/2005 forces special producers, who have power plants with more than $10 \mathrm{MW}$ of installed power, to have their telemeasurement in real-time associated to a centralised dispatching.

Finally the System Operator proceedings explain clearly step by step, the way System Operator dispatches all de energy evacuated from producers to the transport network, including cases of emergency and faults, when frequency, current and voltage are out of normal values, guaranteeing in any moment the supply continuity, security and reliability in the whole system.

\section{Participation in liberalised market: main problems special regime producers find and Power system have}

Owners of special regime producers find some difficulties when they choose to change from a regulated market to liberalised market:

\section{A. Technical}

The system operator limits the system access capacity and the system operation to maintain system stability. Operation Proceedings should be adapted to the new renewable technologies. The share special regime have in the system is growing. Usually these generators are difficult to manage, and their operation has to be adapted to be more likely to the ordinary generators. But the system is not yet prepared to have more production in reserve and production of reactive power.

Those problems will be to some degree reduced when most of the special generators (those who have more than $10 \mathrm{MW}$ installed power) will be associated to a central dispatching and also connected in real-time with the dispatching of the operator System [2].

In the case of wind power generation, it should not be disconnected from the transport network even though slightly disturbances occurred. In the case of voltage flickers that take place in the system, eolic generators are programmed to disconnect automatically. This disconnection could mean an immediate massive loss of production in a network zone and that could cause the connection of other ordinary producers to increase ancillary services to regulate this immediate lack of supply. The transport of huge energy from a zone to another puts transport network in proof. The RD $436 / 2004$ establishes economic complements to the eolic generators that install special equipment to avoid these automatic disconnections from network and ensure supply continuity.

Some renewable technologies are not able to solve neither technical constrains nor voltage control and can not participate on electric power market [2].

In the last year renewable energy is increasing its participation in the power system and seems evident that ancillary services in operating market will be more needed. In order to manage these services quickly, the rest ordinary generators skilled offering these services, will have to adapt their operation. For example, the bombing generators will purchase the energy wind generators sells in off-peak hours [3].

\section{B. Retributive}

Nowadays regulated special regime with more than 10 MW installed power, are obliged to communicate their forecast selling to the distribution company (except renewable generators)[2]. In January 2006, each regulated renewable producer will also have to forecast its selling and communicate it (except photovoltaic generators)[3].

Feedings tariffs for biomass are insufficient.

The liberalised market are structured in various sessions during the day. The most important sessions, in which almost all the energy is purchased, are:

1) The daily market. The market operator collects, at 10:00h every day, all the bids from seller and buy agents, for the compromised energy transactions for the next day.

2) The intra-day market sessions. The market operator collects six times a day all the bids from seller and buy agents, for the compromised energy transactions for the present day. There is one session every three or four hours.

There is a lack of good forecasts in short-medium term (intra-day and daily) of surface wind speed and sun radiation. Renewable producers with solar and eolic technologies have great difficulties to forecast their production (and to bid it) in advance, as the royal decrees explain for the daily market, and to some point, for the intra-day market.

That can lead to a great deviation (difference between real energy sold and the forecasted) and an economic penalty.

The plants built to be connected to distribution network are paid by the promoters, not only the plant itself, but also all the electric devices to make possible to evacuate energy produced to the place distribution network is 
allocated. All these electric devices have to be transferred to the distribution company, in order to maintain and manage them. The distribution company does not receive any retribution of the maintenance and management of these electric devices connected in distribution network from the regulator, but does receive from the ones connected to transport network.

\section{Administrative.}

The administrative proceedings related to legislation of technical characteristics: to go in duty special regime power plants, to be registered in the Register of special regime power plants, to access and connect to distribution-transport network, etc. are so many and takes much time.

\section{Implications on tariff}

To maintain the system of feeding tariffs of special regime producers' retribution, last studies [3], [4] shows that the supply regulated tariff must increase. Even though the access tariff too. That is reflected in the last RD 1454/2005: the average increase in tariffs, related to 2004 , has been $4,48 \%$.

\section{E. Other}

The system operator needs a monitoring real-time measurements (instant power, voltage and current) and market operator needs the statutory measurement. Usually both meters are not installed in the same place. When this occurs, the energy measured is not the same. That leads a difference between the settlement of deviation monitored in real-time by system operator and the deviation settled by market operator.

Special producers (except the renewable technologies of group b) of RD 436/2004) [2] can only sell in market if they sell surplus energy. The Royal Degrees fixed the percentage of energy self-consumed. The renounce to the feeding tariffs by the producer allows him to sell all the energy produced. The renewable producer can sell all he produces.

\section{Possibilities and opportunities renewable energy generators have in liberalised market}

Since the figure of the sales agent was introduced in RD841/2002 and clarified in RD436/2004 to represent special regime producers, many seller agents offers them different services. Usually these agents have a great experience on sales in Electric Market: they represented ordinary producers. This service allows the seller agent to balance deviations between all the special regimes represented by him in electric market, minimise economic penalty deviation, and offer the producer other services like management, consulting of information to send to operator and market system (bids, real measures statutory and real-time telemeasurement, forecasts, settlement).
One important thing that differentiates special regime producers from the ordinary ones is that, special regimes can buy their consume (respecting the percentage of selfconsume) to resellers (buyer agents) or directly in the market, like all the other Spanish consumers since $1 / 1 / 2003$. The difference between the prices of sell and buy, results in an important income for the special producer. And renewable ones sell all they produce, not only the surplus energy, which means more income than the no-renewable special producers.

But not all the technologies of renewable energies have a huge income thanks to the feedings tariff. That depends on the technology, installed power and retributive economical regime (Fig.1, 2, 3).

Since now, the wind production in Spain is the technology that sells almost all its production in electric market (Fig.1).

Special regimes, in general, are accustomed to make their selling bid (for daily and intra-day markets) with price 0 cent $€ / \mathrm{KWh}$. That type of bid assures them that is going to be successfully matched in daily and also intra-day markets. And of course has an advantage, this bid ensures the producer that in the process to solve technical restrictions made by the system operator after the daily market and previous to the intra-day sessions, is not going to be removed or canceled. Through this way, special producers have found an easy manner to produce continuously without any shut down (except the annual technical shut down for maintenance).

\section{Results in liberalised market}

The results for de eolic generators in RD 436/2004 (market) during 2005 are quite good. Their income have increase due to the high prices registered in pool. In general terms the price of the regulated regime was between 62 and $79 € / \mathrm{MWh}$ while in the market has registered $89 € / \mathrm{MWh}$. Basically because the ordinary producers were obliged to internalised in their bids the high costs fossil combustible (petrol, gas) have registered and also have started to internalised the cost of the emissions market of $\mathrm{CO} 2$.

\section{cent $€ / k$ Average price sales of special regime: Wind. iN/h}

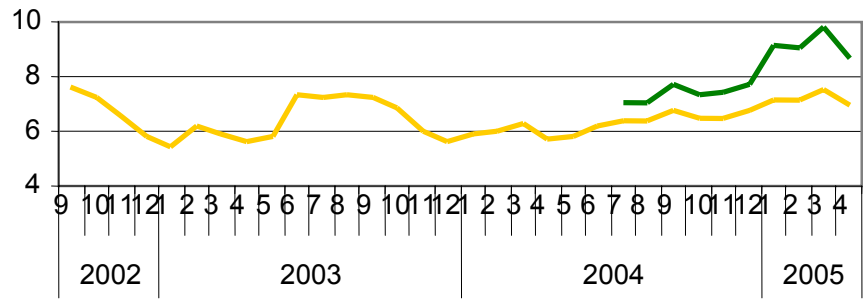


Average price sales of special regime: Hydraulic cent $\epsilon / \mathrm{kWh}$

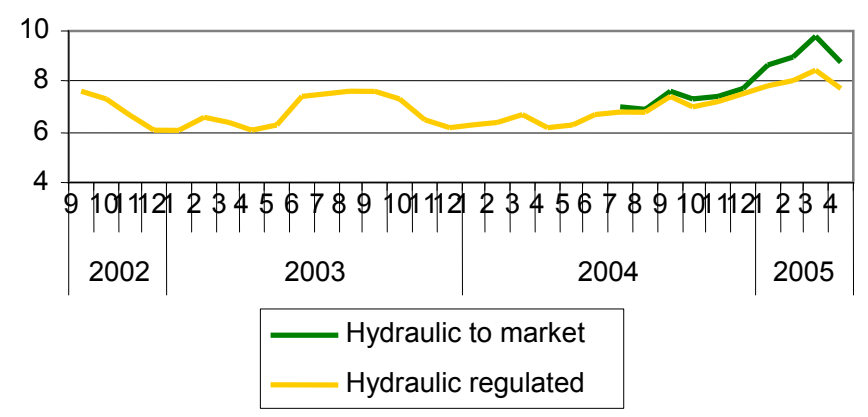

Fig.2. (Source: CNE)

Average price sales of special regime: Biomass. cent€/kWh

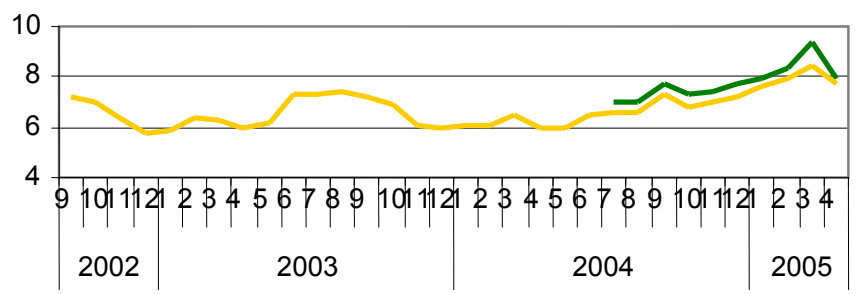

Fig.3. (Source: CNE)

\section{Conclusion}

Producers with more than $10 \mathrm{MW}$ installed power plants, whether they choose regulated or liberalised regime, must accomplish severe requirements: a) in both cases the plants have send real-time measurements to a centralised dispatching, b) must install statutory meters, c) have to predict and inform their production in advance to the Distributor (regulated producers) and Market Operator (liberalised producers) and d) assume their economic penalty deviation.
It seems clear, that all these obligations are needed in order to maintain the safety of system operation. But in the other side, special producers have their incomes assured during a long period of time, thanks to the stability of the tariffs, and laws foment their participation in the pool with the feeding tariffs and incentives. Last year results show clearly that its worth to take part in the market (Fig. 1, 2, 3).

More over, a worldwide tendency in almost all the countries is to involve all the special regime producers (renewable are included here) in an Electricity Market, in order to contribute to the supplies reliability and to reduce the $\mathrm{CO} 2$ emissions.

Governments sensitised with the environmental protection, agreed in the Kyoto protocol to reduce their $\mathrm{CO} 2$ emissions, to the emissions level of the 1990, by means of applying new techniques on old ordinary producers and fomenting the promoters to build new renewable generators, and allowing technologies that use a mixture of fossil and biomass combustible. The Market of emissions has already begun.

Both Markets (emissions and electric) tends to have the same objective: foment the renewable energy producers.

\section{References / Bibliography}

[1] Law 54/97 and Royal Decree Laws that develop it (Spanish Government).

[2] Law 6/2000 and Royal Decree Laws that develop it (Spanish Government).

[3] J. Ignacio Perez Arriaga "Libro Blanco sobre la reforma del marco regulatorio de la Generación Eléctrica en España" (june 2005).

[4] "Informe sobre las Ventas de Energía del Régimen Especial en España - Año 2004". CNE- National Energy Commission of Spain. 